FACULdADE DE CIÊNCIAS ECONÔ MICAS DA UFRGS

MACROECONOMIA DO BRASIL PÓS-1994 LUIZ CARLOS BRESSER-PEREIRA

DESENVOLVIMENTO ECONOMMICO, PREFERÊNCIA PELA LIQUIDEZ E ACESSO BANCÁRIO: UM ESTUDO DE CASO DAS MESORREGIÓES DE MINAS GERAIS

MARCO CROCCO, CLAUDIO BARRA DE CASTRO, ANDERSON CAVALCANTE E VANESSA DA COSTA VAL

FRIEDMAN E O MONETARISMO: A VELHA TEORIA QUANTITATIVA DA MOEDA E A MODERNA ESCOLA MONETARISTA

GENTIL CORAZZAE RODRIGO L. KREMER

BOLLHAS RACIONAIS, CICLO DE PREÇOS DE ATIVOS E RACIONALIDADE LIMITADA: UMA AVALIACAOO CRITICA DOS MODELOS NEOCLÁSSICOS DE BOLHAS ESPECULATIVAS JOSÉ LUIS OREIRO

VULNERABILITY INDICATORS OF THE TWIN CRISES: THE EAST ASIAN EPISODE

TITO BELCHIOR SILVA MOREIRA

IMPACTOS POTENCIAIS DA NEGOCIAÇÃO DA ALCA SOBRE OS INVESTIMENTOS EXTERNOS EM SERVIÇOS PROFISSIONAIS NO BRASIL

MICHEL ALEXANDRE, OTAVIANO CANUTO E GILBERTO TADEU LIMA

TEORIA MARXISTA DO VALOR: UMA INTRODUÇẢO ALFREDO SAAD FILHO

UM ESTUDO EMPIRICO DOS CICLOS POLITICO. ECONOOMICOS NO BRASIL

ATHOS PRATES DA SILVEIRA PREUSSLER E MARCELO SAVINO PORTUGAL

RELENDO CHANDLER, WILLIAMSON E NORTH PARA ENTENDER O PROCESSO DE FORMACĀO DAS ESTRADAS DE FERRO NO BRASIL

JEFFERSON ANDRONIO RAMUNDO STADUTO

WEIMAR FREIRE DA ROCHA IR. E CLAIITON ATAIDES DE FREITAS

MATRIZ DE INSUMO-PRODUTO PARA A ECONOMIA TURISTICA BRASILEIRA: CONSTRUCCÃO E ANÁLISE DAS RELAÇÓES INTERSETORIAIS

FRANCISCO CASIMIRO FILHO E JOAQUIM JOSÉ MARTINS GUILHOTO

SEÇĀO ESPECIAL: AVALIAÇŌES INICIAIS DA POLITTICA ECONÓMICA DO GOVERNO LULA

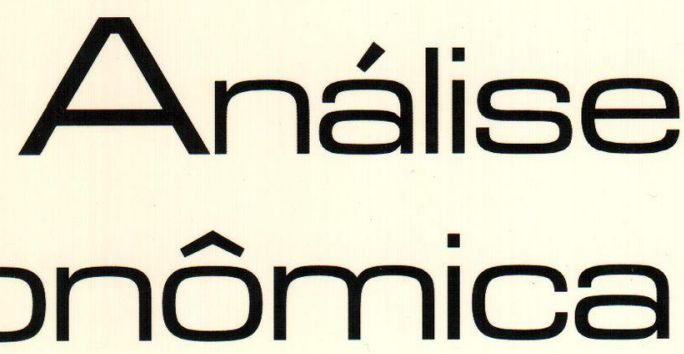


Universidade Federal do Rio Grande do Sul

Reitora: Profa. Wrana Maria Panizzi

Faculdade de Ciencias EConómicas

Diretora: Prof Pedro César Dutra Fonseca

Centro de Estudos e Pesquisas Economicas

Diretor: Prof. Gentil Corazza

Departamento de Ciéncias económicas

Chiefe: Prof. Ricardo Dathein

Curso de Pós. Graduação em Economia

Coordenador: Prof. Eduardo Pontual Ribeiro

Programa de Pós-Graduação em Desenvolvimento Rural

Coordenador: Prof. jalcione Almeida

CONSElHo EDITORIAL:

Carlos G. A. Mielitz Netto (UFRGS), Eduardo A. Maldonado Filho (UFRGS), Eduardo P. Ribeiro (UFRGS), Eleutério F. S. Prado (USP), Eugênio Lagemann (UFRGS), Fernando Cardim de Carvalho (UFRJ), Fernando Ferrari Filho (UFRGS), Fernando de Holanda Barbosa (FGV/RJ), Flávio Vasconcellos Comim (UFRGS), Gentil Corazza (UFRGS), Giácomo Balbinotto Netto (UFRGS), Gustavo Franco (PUC/RJ), Jan A. Kregel (UNCTAD), João Rogério Sanson (UFSC), Joaquim Pinto de Andrade (UnB), Jorge Paulo Araújo (UFRGS), Marcelo S. Portugal (UFRGS), Maria Alice Lahorgue (UFRGS), Paul Davidson (University of Tennessee), Paulo D. Waquil (UFRGS), Pedro C. D. Fonseca (UFRGS), Philip Arestis (Levy Economics Institut of Bard College), Roberto C. de Moraes (UFRGS), Ronald Otto Hillbrecht (UFRGS), Sabino da Silva Porto Jr. (UFRGS), Stefano Florissi (UFRGS) e Werner Baer (University of Illinois at UrbanaChampaign).

COMISSÃO EDITORIAL:

Eduardo Augusto Maldonado Filho, Fernando Ferrari Filho, Gentil Corazza, Marcelo Savino Portugal, Paulo Dabdab Waquil e Roberto Camps Moraes.

EDIroR: Prof. Fernando Ferrari Filho

Editor Adunnio: Prof. Gentil Corazza

SECRETÁrla: Clarissa Roncato Baldim

REVISÁO DE TEXTOS: Vanete Ricacheski

EDITORaÇão Eletrónica: Vanessa Hoffmann de Quadros

Fundador: Prof Antônio Carlos Santos Rosa

Os materiais publicados na revista Análise Econômica são da exclusiva responsabilidade dos autores. É permitida a reprodução total ou parcial dos trabalhos, desde que seja citada a fonte. Aceita-se permuta com revistas congêneres. Aceitam-se, também, livros para divulgação, elaboraçāo de resenhas e recensōes Toda correspondência, material para publicaçāo (vide normas na terceira capa), assinaturas e permutas devem ser dirigidos ao seguinte destinatário:

Análise Econômico

PROF FERNANDO FERRARI FILHO Revisła Análise Econômica - Av. João Pessoa, 52 CEP 90040-000 PORTO ALEGRE - RS, BRASL Telefones: (051) 316-3513 - Fax: (051) 316-3990 E-mail: rae@ufrgs.br

Ano 21, $n^{\circ} 39$, março, 2003 - Porto Alegre

Faculdade de Ciências Econômicas, UFRGS, 2003

Periodicidade semestral, março e setembro.

Tiragem: 500 exemplares

1. Teoria Econômica - Desenvolvimento Regional.

Economia Agrícola - Pesquisa Teórica e Aplicada -

Periódicos. I. Brasil

Faculdade de Ciências Econômicas,

Universidade Federal do Rio Grande do Sul 


\title{
Desenvolvimento econômico, preferência pela liquidez e acesso bancário: um estudo de caso das mesorregiões de Minas Gerais
}

\author{
Marco Crocco* \\ Cláudio Barra de Castro** \\ Anderson Cavalcante* \\ Vanessa da Costa Val ${ }^{* *}$
}

\begin{abstract}
The aim of this paper is to study the bank access and the public liquidity preference in Minas Gerais. The theoretical approach will be postkeynesian, which suggests that in peripherical regions the liquidity preference would be higher, due to the uncertainty. This situation leads to fewer agencies, less information within the peripheral region and lower willingness in lending by the bank system. In this way, regions with higher liquidity preferences and lower bank access are supposed to show credit problems, what make their development more difficult.
\end{abstract}

Key Words: economic development, financial system, post-keynesian. JEL Classification: E60, G21, R12.

\section{Introdução}

Os estudos sobre a questão regional brasileira sempre se caracterizaram pelo estudo do comportamento das variáveis reais da economia (produção, emprego, salários etc.). Além disto, destaca-se também o fato de que variáveis monetárias e financeiras serem recorrentemente negligenciadas em tais estudos. Tal perspectiva pode ser justificada por três fatores determinantes (Amado, 1998, p. 418): i) a influência da escola neoclássica nos estudos regionais. Como se sabe, tal escola caracteriza a moeda apenas como um meio de troca não sendo capaz de afetar as variáveis reais da economia; ii) a aceitação, por parte daqueles que discordam da escola neoclássica,

\footnotetext{
- Professor Adjunto do Departamento de Ciências Econômicas e do CEDEPLAR - UFMG. Email: crocco@cedeplar.ufmg.br. Os autores agradecem à FAPEMIG por propiciar os recursos necessários a produção deste artigo, através do seu financiamento à pesquisa Sistema Financeiro e Polarização Regional.

* Do CEDEPLAR - UFMG.
} 
da concepção horizontalista de oferta de moeda. Tal concepção entende que a oferta de moeda é acomodativa das variáveis reais, sendo capaz de variar para atender a qualquer padrão de demanda por moeda. Desta forma, a oferta de moeda não possuiria a capacidade de afetar a dinâmica econômica; iii) a ausência de dados satisfatórios para uma análise da questão regional sob a ótica financeira e monetária.

Dentre os fatores listados acima, apenas o último pode ser considerado como elemento efetivamente limitador da análise financeira nas questōes regionais. No entanto, apesar destas dificuldades, estudos recentes (Amado 1997, 1998 e 1999) mostraram que é possível fazer inferências relevantes sobre o tema.

Tendo em vista estimular estudos sobre a influência da moeda no desenvolvimento regional, o objetivo deste artigo é analisar o acesso bancário e a preferência pela liquidez do público em Minas Gerais, com base na divisão em mesorregiōes geográficas do IBGE. A hipótese principal é que as regiōes do Estado definidas como mais centrais apresentam menor preferência pela liquidez e maior acesso bancário relativamente às regióes mais periféricas. $\mathrm{O}$ artigo, além desta breve introdução e uma conclusão, apresenta mais três seções. Na primeira, discute-se o arcabouço teórico relativo à economia regional vis-à-vis a economia pós-keynesiana por detrás das hipóteses levantadas. Na segunda seção, são apresentadas a fonte de dados e a metodologia utilizada para a análise das hipóteses no cenário escolhido. A seção três traz os resultados obtidos e as inferências sobre esses resultados, através de duas subseçōes: uma descrevendo brevemente os dados e a outra os analisando através das técnicas estatísticas utilizadas.

\section{Preferência pela liquidez e desenvolvimento econômico: considerações teóricas}

Uma característica marcante na literatura acerca de economia regional é o pouco destaque dado à moeda e o seu papel para o desenvolvimento regional. Vários modelos de determinação da renda regional, como o neoclássico, o de causação cumulativa e o de insumo-produto, não consideram o impacto da moeda e de variáveis financeiras. Quando abordadas, tais variáveis são em sua maioria tratadas em modelos econométricos, nos quais algumas variá- 
veis monetárias nacionais consideradas exógenas afetam a determinação regional da renda em função das características específicas de cada região. Assim, a moeda e os fluxos monetários têm sido con siderados como o resultado da diferença entre regiões e não como a causa desta diferença.

Segundo Rodriguez-Fuentes (1998), as principais razões para esta ausência de referências a fatores monetários são: 1) a hipótese ortodoxa de que a moeda é neutra no longo prazo e, assim sendo, não poderia explicar valores reais em nível regional; 2) o fato de regiōes não usarem instrumentos de política monetária, o que as deixa sem importância para estudo; 3) o fato de regiões serem extremamente abertas e enfrentarem uma perfeita mobilidade de capital, tal como uma pequena e aberta economia.

Embora as raízes de diferenças de renda regionais possam ser achadas em fatores estruturais, variáveis monetárias podem ser responsáveis pela manutenção e ampliação das diferenças de renda regional, quando se adota uma abordagem em que a moeda e os bancos são sempre não neutros para o desenvolvimento regional. Trabalhos nesta linha de abordagem, de cunho pós-keynesiano, surgiram recentemente na literatura econômica'.

A teoria monetária pós-keynesiana considera a moeda como uma parte integral do processo econômico e, desta forma, uma clara distinção entre o lado monetário e o real da economia não pode ser feita (DOW, 1993). Para os pós-keynesianos, a moeda não é exógena e entra no sistema através do crédito gerado pelos bancos e induzido pela sua demanda, onde merece atenção a demanda por moeda devido ao motivo finance, por ser o ponto de partida para a geração de renda. Assim, o crédito permite determinar o investimento em vez de determinar o nível geral de preços, tornando a moeda parte integrante do processo econômico e não neutra.

A análise pós-keynesiana também se distingue das demais por abordar tanto o lado da oferta quanto o lado da demanda no mercado de crédito regional. Para esses autores ${ }^{2}$, a oferta e a demanda de crédito são interdependentes e afetadas pela preferência pela liquidez, vinculada às expectativas que os agentes formam em um

\footnotetext{
${ }^{1}$ Para um estudo empírico desta teoria em nível internacional ver Dow (1990). Ver Amado (1997) para a aplicação ao caso brasileiro.

${ }^{2}$ Para esclarecimentos sobre preferência pela liquidez dos bancos, ver Carvalho (1999), Paula (1999) e Dow (1988).
} 
ambiente de incerteza ${ }^{3}$. Do ponto de vista dos bancos, a preferência pela liquidez afetará negativamente a sua disposição em emprestar na região, caso possuam expectativas pessimistas ou pouco confiáveis sobre a mesma. No lado da demanda por crédito, a preferência pela liquidez do público afetará suas respectivas definiçōes de portfólio. Quanto maior a preferência pela liquidez, maior as posições em ativos líquidos destes agentes e menor sua demanda por crédito.

A partir destes conceitos teóricos e utilizando-se de elementos da Teoria da Causação Cumulativa e da Dependência, Dow (1982 e 1987) apresenta alguns modelos em que o sistema financeiro, juntamente com o lado real da economia, pode promover padrões de desenvolvimento regional desiguais. Dow (1982) tenta traduzir os argumentos de liquidez para um contexto espacial. Assim, economias contemporâneas com igual base monetária possuiriam multiplicadores monetários mais elevados quanto mais otimistas fossem as expectativas sobre os preços locais dos ativos; mais líquidos os mercados locais destes ativos; maior o grau de desenvolvimento financeiro e mais favorável seu resultado comercial com outras regiōes.

Dois casos extremos de regiões com diferenças em suas características são considerados: uma região central e uma periférica. $O$ centro seria uma região próspera, com mercados ativos e sofisticação financeira. A periferia seria uma economia estagnada, com tênues mercados e um menor grau de sofisticação financeira ${ }^{4}$. Como resultado destas características, a preferência pela liquidez seria maior na periferia, a liquidez de qualquer ativo seria maior no centro do que na periferia e, no longo prazo, o multiplicador bancário seria maior no centro. Além disto, a contextualidade espacial permite que o agente possa manter, simultaneamente, ativos de economias de várias regiōes, implicando não só a endogenização espacial da base monetária, como também reforçando o caráter distinto das ofertas de moeda regionais ${ }^{5}$.

\footnotetext{
${ }^{3}$ Incerteza neste caso diferencia-se de risco e pode ser identificada por sua característica de ser nāo-mensurável, ao contrário do conceito de risco, o qual pode ser medido em termos quantitativos (KNIGHT, 1991). Para um aprofundamento sobre a utilização deste conceito na economia keynesiana, ver Davidson (1982/1983, 1993 e 1995), Dow (1995), Crocco (1999) e Dequech (2000).

${ }^{4} \mathrm{O}$ modelo considera que, mesmo dentro de uma nação, as inovações financeiras somente se estendem do centro financeiro para regiōes mais remotas após um certo lag de tempo e que custos de transações adicionais e de informação ajudam a preservar esta diferença.

${ }^{5}$ Dow (1982) trabalha com um sistema bancário de base regional. Entretanto, seus argumentos de diferenças na oferta de moeda continuam válidos em um sistema bancário nacional onde o fluxo de capitais pode ser exacerbado e a destinação das alocações dos recursos dependem crucialmente das decisões do centro, para onde o capital flui e os níveis de depósitos são maiores.
} 
Em sua analise de 1987, Dow concentra-se nas idéias de Causação Cumulativa de Myrdal (1957), adotadas por keynesianos como Kaldor (1970), e na Teoria da Dependência associada com neomarxistas como Baran (1957), Frank (1966) e Cardoso (1792,1973,1978 e 1979). Em acordo com a teoria da causação cumulativa, a autora expõe que um dos setores da região central que aproveitará economias dinâmicas de escala é o setor financeiro. $\mathrm{O}$ fato de instituições financeiras tenderem a ter escritórios centrais na região central implica um distanciamento das demandas por investimento na região periférica e dificuldade na concessão de crédito. Dado este cenário de concentração espacial de decisão, as linhas da abordagem neomarxista são importantes por esclarecerem que o poder sobre a provisão de crédito não só pode gerar problemas de disponibilidade deste para a região periférica, como também pode ser viesado para tipos particulares de indústrias. Há, portanto, uma separação entre o local do investimento e o local de controle e, desta maneira, a forma como este investimento se realiza é que assegura a dependência e o subdesenvolvimento.

$O$ centro é definido como um local que apresenta uma estrutura produtiva historicamente dominada pela indústria e pelo comércio, e onde se situa o centro financeiro. A periferia, por sua vez, concentra suas atividades no setor primário e nas manufaturas de baixa tecnologia, com uma dinâmica econômica centrada na exportação para o centro, sendo as receitas de suas vendas sensíveis à conjuntura no centro e, conseqüentemente, altamente voláteis. $\mathrm{O}$ centro possui spread effects sobre a periferia não apenas nas suas demandas de produtos, mas também na difusão de tecnologia, mãode-obra qualificada e serviços através de suas filiais, promovendo uma dependência centro e periferia.

Estas características implicam que a preferência pela liquidez irá ser maior na periferia para os seus residentes, sejam bancos, empresários e o público. As razōes para tal seriam o alto risco de perda de capital para os bancos, relacionados ao risco de default dos empréstimos; a mudança da eficiência marginal do investimento para as empresas, que é afetada pela menor disponibilidade de empréstimos e maior juros bancários; e a incerteza na obtenção de renda percebida pelo público, ambos ligados à volatilidade da economia.

O resultado é que bancos nacionais podem emprestar menos para a periferia dada sua estrutura econômica e o remoto controle 
sobre as sua filiais. Bancos específicos da periferia, por sua vez, irão preferir manter um nivel de reservas mais altos e restringir os empréstimos locais, colocando-se em uma posição de desvantagem relativa e encorajando a concentração bancária no centro. Além disto, a maior preferência pela liquidez do público na periferia se traduziria em maior parcela de depósitos a vista sobre depósitos a prazo, o que poderia obrigar os bancos a diminuírem o prazo de seus empréstimos para ajustarem-se ao menor prazo dos depósitos, gerando menos recursos de longo prazo para a região.

Portanto, a indicação destes modelos é que regiões com baixo acesso bancário e alta preferência pela liquidez do público podem sofrer de restrição de crédito por parte do sistema bancário e terem o seu desenvolvimento dificultado, criando um circulo vicioso econômico-financeiro nestas regiões. Este arcabouço teórico servirá como referência para o estudo do Estado de Minas Gerais a ser feito nas próximas seções.

\section{Fontes de dados e Metodologia}

\subsection{Fonte de Dados}

A unidade básica neste trabalho são as mesorregiōes geográficas do Estado de Minas Gerais, definidas segundo classificação do Instituto Brasileiro de Geografia e Estatística (IBGE). Esta divisão recorta o estado em doze mesorregiões, conforme o mapa abaixo.

\section{Mapa 1: Mesorregiões Geográficas de Minas Gerais (IBGE)}

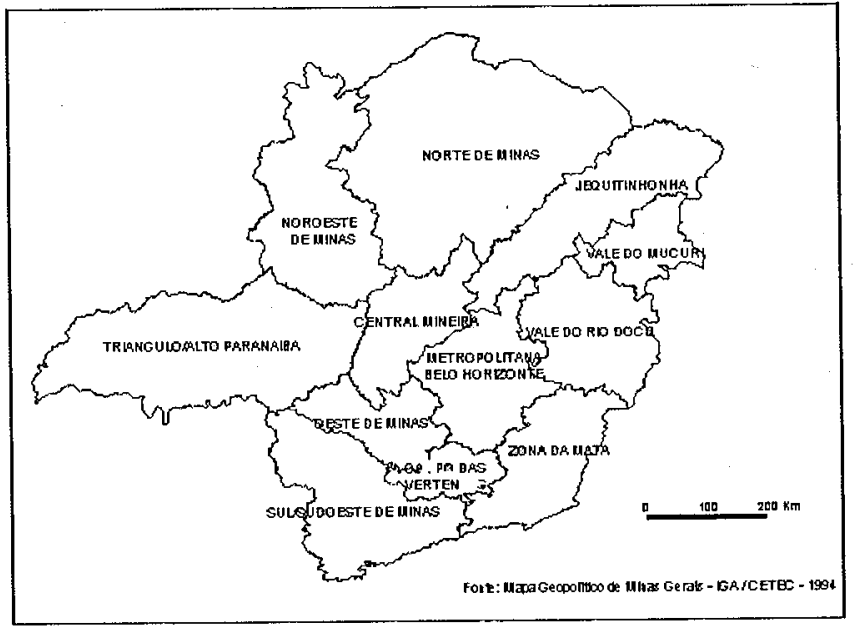


A análise utiliza dados relativos ao sistema financeiro e de características econômicas das mesorregiōes. As variáveis e indicadores utilizados são o Produto Interno Bruto (PIB), o número de estabelecimentos do setor serviço com mais de dez empregados, a população total, o grau de urbanização, o número de agências bancárias, o acesso bancário relativo, a relação agência sobre PIB relativamen. te ao Brasil (chamado ICB - Índice de Concentração Bancária) e a preferência pela liquidez do público (PLP).

O dados de PIB, população, estabelecimentos do setor serviço com mais de dez empregados e grau de urbanização permitem uma caracterização do desempenho econômico da regiāo e de seu grau de centralidade. O grau de urbanização é obtido pela divisão da população urbana pela população total na mesorregião. Em relação às variáveis financeiras, definiu-se o acesso bancário relativo a partir da seguinte fórmula:

$\frac{A G m / A G b}{P O P m / P O P b}$

onde $A G m$ é o número de agências bancárias por mesorregião; $A G b$ é o número de agências bancárias no Brasil;

POPm é a população da mesorregião;

$P O P b$ é a população do Brasil.

Esse índice reflete a situação da mesorregião comparativamente à situação do Brasil. Quando o índice for maior que 1, significa que o número de agências existentes na mesorregião é relativamente maior ao número de agências existentes no Brasil, em comparação com sua participação na população. Isso quer dizer que o número de agências por habitante é maior que a média brasileira. Este indicador e o indicador do número de agências representam o acesso bancário na região e, quanto maior seus valores, melhor a regiāo está, pois quanto maior é a presença e a proximidade física de agentes bancários e não bancários, melhor deve ser a quantidade e a qualidade da informação sobre os negócios e a demanda de crédito na região, o que em teoria gera uma menor incerteza sobre o merecimento de crédito na região e uma maior possibilidade de oferta de crédito na região.

A relação agência sobre PIB relativamente ao Brasil (ICB) tem a fórmula:

$A G m / A G b$

$P I B m / P I B b$ 
onde $A G m$ é o número de agências bancárias por mesorregião; $A G b$ é o número de agências bancárias no Brasil;

PIBm é o produto interno bruto da mesorregião;

$P I B b$ é o produto interno bruto do Brasil.

Quando este índice for maior que 1 , significa que o número de agências existentes na mesorregião é relativamente maior ao número de agências existentes no Brasil, em comparação com sua participação no PIB. Isso quer dizer que o número de agências em relação ao PIB é maior que a média brasileira. Tal estaria indicando uma maior parcela de inativos na região, representando uma diferença acentuada entre renda e produto na região. Espera-se que este indicador seja elevado em regiões mais pobres.

O índice de preferência pela liquidez do público é definido como sendo a participação em cada município da mesorregião dos depósitos a vista nos depósitos totais, o qual é composto pela soma dos depósitos a vista mais poupança e mais depósitos a prazo. Com esse índice, é possível ter uma noção do comportamento dos agentes da região quanto à manutenção de ativos mais ou menos líquidos. Quanto maior o índice, mais os agentes preferem manter seus ativos líquidos, indicando uma maior preferência pela liquidez na região.

Os dados do sistema financeiro sobre número de agências de bancos múltiplos e comerciais, tanto públicos quanto privados, presentes em cada município, sobre os depósitos a vista e os depósitos totais foram disponibilizados pelo Banco Central do Brasil (BACEN).

Os dados de PIB foram obtidos através do PIB por município da Fundação João Pinheiro (F.JP). Os dados de população tiveram como fonte o IBGE. Os dados de número de estabelecimentos do setor serviço foram coletados na Relação Anual das Informações Sociais do Ministério do Trabalho (RAIS/MT).

Para auxiliar na caracterização das regiões administrativas e de seus papéis como regiões centrais ou periféricas foram utilizados diagnósticos realizados pela FJP, pelo Banco de Desenvolvimento de Minas Gerais (BDMG) e o estudo feito por Lemos, M.; Guerra, L.; Moro, S. (2000), onde se faz uma regionalização econômica do Brasil capaz de definir regiões pólos e polarizadas. 


\subsection{Metodologia}

Neste trabalho foram utilizadas duas técnicas estatísticas de análise multivariada: a análise de componentes principais (ACP) e a análise de cluster. Estas técnicas permitem apresentar as principais características de cada regiāo e formar agrupamentos de regiões de acordo com a similaridade de desempenho nos dados utilizados ${ }^{6}$.

A técnica de análise de componentes principais (ACP) tem como objetivo básico construir um conjunto de variáveis $Z_{n}$ estatisticamente independentes, formadas a partir de uma transformação linear do conjunto de variáveis observadas. As variáveis observadas precisam ser correlacionadas no início do processo e não é necessário fazer suposiçōes iniciais a respeito da distribuição de probabilidade das variáveis originais.

Cada variável $Z$ será chamada de componente principal e construída da seguinte forma:

$$
Z_{n}=a_{n 1} X_{1}+a_{n 2} X_{2}+\ldots+a_{n n} X_{n}
$$

Pode-se, então, definir quanto da variação total das variáveis $X$ o componente principal é capaz de reproduzir, e quais coeficientes de suas equações são diferentes de zero. As variâncias de $Z_{\mathrm{i}}$ são obtidas a partir dos autovalores da matriz de covariância das variáveis observadas, e os autovetores, associados a estes autovalores ordenados, fornecem os coeficientes para os componentes principais. $\mathrm{O}$ primeiro componente principal $Z_{1}$ explicara o maior percentual de variação nos dados observados, o segundo componente $Z_{2}$ explicará a segunda maior variação, e assim sucessivamente, de modo que se tem:

\section{$\operatorname{Var}\left(Z_{1}\right) \geq \operatorname{Var}\left(Z_{2}\right) \geq \ldots \geq \operatorname{Var}\left(Z_{n}\right)$}

onde $\operatorname{Var}(Z)$ é a variância de $Z$ nos dados observados.

Em função do tipo de variáveis com coeficientes significativamente diferentes de zero que os compõem, os componentes principais podem ser nomeados de acordo com as características que traduzem e, dependendo do grau de variância das variáveis que reproduzem, podem ser considerados ou não relevantes para a análise.

Realizada a ACP, é possivel determinar qual valor cada região atinge em cada componente principal e, também, representar as regiōes em um plano dimensional onde os componentes formam os eixos, de modo a se perceber o posicionamento conjunto das regi-

\footnotetext{
- Ver a respeito destas técnicas, Pereira (2001), Andrade (1989) e Mardia; Kent; Bibby (1988).
} 
ões nos valores dos componentes principais e quais variáveis melhor explicam seu posicionamento.

A técnica de análise de cluster permite que agrupamentos de regióes possam ser formados de acordo com a similaridade de desempenho nos indicadores utilizados, de modo que indivíduos com desempenho próximo nos indicadores da análise fiquem no mesmo grupo.

Existem várias técnicas de análise de cluster, as quais permitem diferentes medidas de similaridade e métodos de formação de grupos. Neste trabalho, escolheu-se o método hierárquico aglomerativo. Neste método, cada um dos $n$ indivíduos é considerado de início como sendo um grupo, os quais irăo se agrupando e formando novos grupos em função de suas similaridades até que se chegue em um único grupo de $n$ indivíduos. Os agrupamentos são representados em um dendograma e pode-se definir qual a melhor forma de agrupamento, ou seja, qual a quantidade de grupos melhor separa os indivíduos por similaridade de desempenho nas variáveis.

A medida de distância será a distância euclidiana, e as variáveis serão padronizadas no cálculo da distância. O método de agrupamento será o Average Linkage Between Groups, o qual agrupa o indivíduo no grupo de valor médio na medida de similaridade dos indivíduos que o compõem mais próximo. As técnicas de ACP e análise de cluster serão repetidas para os anos de 1991, 1996 e 2000, propiciando uma análise do movimento das regiōes em três períodos distintos.

\section{Análise dos Dados}

\subsection{Descrição inicial dos dados}

Os dados de PIB apontam para as regiões do centro-sul (Triângulo Mineiro/Alto Paranaíba, Sul/Sudoeste de Minas, Central Mineira, Metropolitana de BH, Oeste de Minas e Zona da Mata) com os maiores PIB e PIB per capita, com destaque para a região metropolitana de Belo Horizonte, a qual possui os maiores valores para ambas as variáveis. As regiões mais ao norte (Noroeste de Minas, Norte de Minas, Jequitinhonha e Vale do Mucuri) apresentam os menores PIB e PIB per capita, com o Jequitinhonha e o Vale do Mucuri tendo os menores valores do Estado.

Os dados populacionais mineiros apontam um aumento da população urbana em detrimento da população rural, fenômeno co- 
mum no atual cenário populacional brasileiro. As mesorregiōes Noroeste de Minas, Vale do Mucuri, Central Mineira, Campo das Vertentes, Jequitinhonha, Vale do Rio Doce e Oeste de Minas mostram um aspecto interessante em suas características populacionais, que é o de manter praticamente inalterada sua população total ao longo do período, mas com aprofundamento do grau de urbanização, o que significa que a população residente varia pouco ou quase nada, com paralela concentração populacional em cidades-pólo, tanto dentro da própria mesorregião quanto dentro de outras mesorregiões. Entre 1991 e 2000, a região Noroeste foi a que mais aumentou seu grau de urbanização, passando de $61 \%$ para $74 \%$. A mesorregião menos urbanizada é o Jequitinhonha, seguida do Norte de Minas e do Vale do Mucuri. A mais urbanizada é a região Metropolitana de Belo Horizonte, seguida pelo Triângulo Mineiro/Alto Paranaíba e o Oeste de Minas.

Os dados do indicador ICB apresentam maiores valores nas regiōes mais ao norte (Noroeste de Minas, Norte de Minas, Jequitinhonha e Vale do Mucuri), indicando que nestas regiões a diferença entre o produto e a renda é maior, possivelmente devido à elevada participação de inativos na geração de renda destas regiões.

O número de agências em Minas Gerais apresentou um aumento de 1991 a 1996, mas decresceu no período entre 1996 e 2000 , principalmente devido ao processo de concentração bancária pósPlano Real. Essa concentração deve-se ao fim da inflação, fonte de ganhos dos bancos, principalmente devido ao floating. Em um ambiente inflacionário, os bancos procuravam inúmeras formas de se beneficiar da situação, captando recursos que não pagam juros como recolhimento de impostos - e investindo em títulos e outros ativos com rendimentos favoráveis, principalmente o overnight. Esse processo incentivava o crescimento das agências bancárias. Entretanto, com o Plano Real e a estabilização da economia, esse privilégio acabou. Aliada à política do governo de privatizações e de incentivo a fusōes no setor bancário, ao incentivo à entrada de bancos estrangeiros no mercado nacional e ao processo de redução da estrutura de custos operacionais dos bancos ${ }^{7}$, configurou-se um quadro de redução no número de agências em todo o país, inclusive em Minas Gerais. Nesse cenário mais reduzido, as regiões que

7 Para maiores esclarecimentos com relação à concentração bancária na década de 90 , ver Rocha (2001) e Madi e Meleti (1995). 
apresentaram maior número de agências no Estado são as Metropolitana de Belo Horizonte, Sul/Sudoeste de Minas e Triângulo Mineiro/Alto Paranaíba. Destaca-se que a participação de Belo Horizonte é cerca de $15 \%$ do total do Estado, número que apresentou uma tendência de aumento nos últimos anos. Em relação ao Brasil, a participação de Minas Gerais no número de agências manteve-se em cerca de $11 \%$.

O índice de acesso bancário absoluto para o Brasil ficou em torno de 10.000 habitantes por agência bancária. Comparando esse dado com o acesso da população nas mesorregiões, tem-se que as regiōes Oeste, Sul/Sudoeste e Triângulo Mineiro mostram-se com uma média maior que a nacional (mais agências por 10.000 habitantes) em 1991. Nos outros dois anos pesquisados, essas regiōes ainda lideram no Estado, mas com ascensão das regiões Metropolitana de Belo Horizonte e Central Mineira. As três regiões com pior índice foram Jequitinhonha, Norte de Minas, Vale do Mucuri e Vale do Rio Doce, com média de 16.000 habitantes por agência.

Em relação à preferência pela liquidez do público (PLP), as regiões mais desenvolvidas em termos de PIB e centralidade apresentaram PLP mais baixa (Triângulo Mineiro/Alto Paraíba, Sul/Sudoeste de Minas, Central Mineira, Metropolitana de $\mathrm{BH}$, Oeste de Minas e Zona da Mata), enquanto as menos desenvolvidas (Noroeste de Minas, Norte de Minas, Jequitinhonha e Vale do Mucuri) apresentaram PLP mais alta. Os destaques são a mesorregião Metropolitana de BH com a mais baixa PLP do Estado e a mesorregião Noroeste de Minas com a mais alta PLP.

\subsection{Análise dos dados através de técnicas estatísticas}

Com base em todas as variáveis e indicadores presentes neste trabalho, realizou-se uma ACP para os anos de 1991, 1996 e 2000. O quadro abaixo apresenta a predominância das variáveis em cada fator nestes anos e também o percentual de variância das variáveis acompanhadas pelos componentes.

Pelo quadro 1 , percebe-se que uma clara definição de que tipo de variáveis cada componente representa não é fácil. Algumas variáveis como a PLP mudam do primeiro para o segundo componente entre 1991 e 1996 e o ICB muda entre 1996 e 2000 do primeiro para o segundo componente. De qualquer forma, o componente 1 parece representar fatores econômicos e de centralidade das regiões, 
pois a ele pertencem as variáveis de PIB, população, número de estabelecimentos do setor serviço e número de agências. O componente 2 representa bem o acesso bancário relativo. $O$ fato é que, apesar da dificuldade em se rotular os componentes, uma apreciação visual da distribuição das mesorregiōes nestes componentes e as indicações de que variáveis mais contribuem para este posicionamento ajudam a entender melhor o impacto dos dados econômicos e financeiros sobre as regiōes. Abaixo são apresentados os resultados gráficos para os períodos de 1991,1996 e 2000.

\section{Quadro 1: Análise de Componentes Principais}

\begin{tabular}{|c|c|c|c|c|c|c|}
\hline & \multicolumn{2}{|c|}{1991} & \multicolumn{2}{c|}{1996} & \multicolumn{2}{c|}{2000} \\
\hline Variável / Componente & $C 1$ & $C 2$ & $C 1$ & $C 2$ & $C 1$ & $C 2$ \\
\hline No agências & 0,41 & $-0,08$ & 0,42 & 0,12 & 0,43 & $-0,08$ \\
\hline Pop Total & 0,40 & $-0,27$ & 0,40 & 0,26 & 0,41 & $-0,21$ \\
\hline Acesso B Relativo & 0,19 & 0,75 & 0,20 & $-0,66$ & 0,22 & 0,62 \\
\hline Est. Serviço >10 empreg. & 0,41 & $-0,19$ & 0,41 & 0,22 & 0,42 & $-0,17$ \\
\hline PIB & 0,41 & $-0,22$ & 0,41 & 0,24 & 0,42 & $-0,19$ \\
\hline ICB & $-0,26$ & $-0,09$ & $-0,27$ & $-0,16$ & $-0,24$ & 0,36 \\
\hline GU & 0,33 & 0,49 & 0,33 & $-0,42$ & 0,33 & 0,36 \\
\hline PLP & $-0,31$ & 0,06 & $-0,29$ & 0,39 & $-0,23$ & $-0,46$ \\
\hline $\begin{array}{c}\text { Variâncias acompanhadas } \\
\text { pelos componentes }\end{array}$ & 0,67 & 0,83 & 0,65 & 0,85 & 0,63 & 0,82 \\
\hline
\end{tabular}

O gráfico 1 apresenta a análise para o ano de 1991. Observa-se que as regiões de maior PIB, população, setor serviço e número de agências apresentam uma menor preferência pela liquidez e menores valores no ICB, o que significa uma relação mais próxima entre renda e produto. Destaca-se, de um lado, a região Metropolitana de Belo Horizonte por seus maiores valores de produto, população, participação do setor serviço e número de agências e menor preferência pela liquidez. As regiões do Jequitinhonha, Vale do Mucuri, de Minas, Norte de Minas e Noroeste de Minas, de outro lado, aparecem na posição inversa, com baixos valores nas variáveis de de- 
sempenho econômico e centralidade e alta preferência pela liquidez. As regiões Triângulo/Alto Paranaíba e Sul/Sudoeste do Estado são as que apresentam melhor acesso bancário relativo e as regiōes da Zona da Mata, Campo das Vertentes, Oeste de Minas, Central Mineira e Vale do Rio Doce têm um comportamento médio nos fatores e, portanto, nas variáveis de análise.

\section{Gráfico 1: ACP para o ano de 1991}

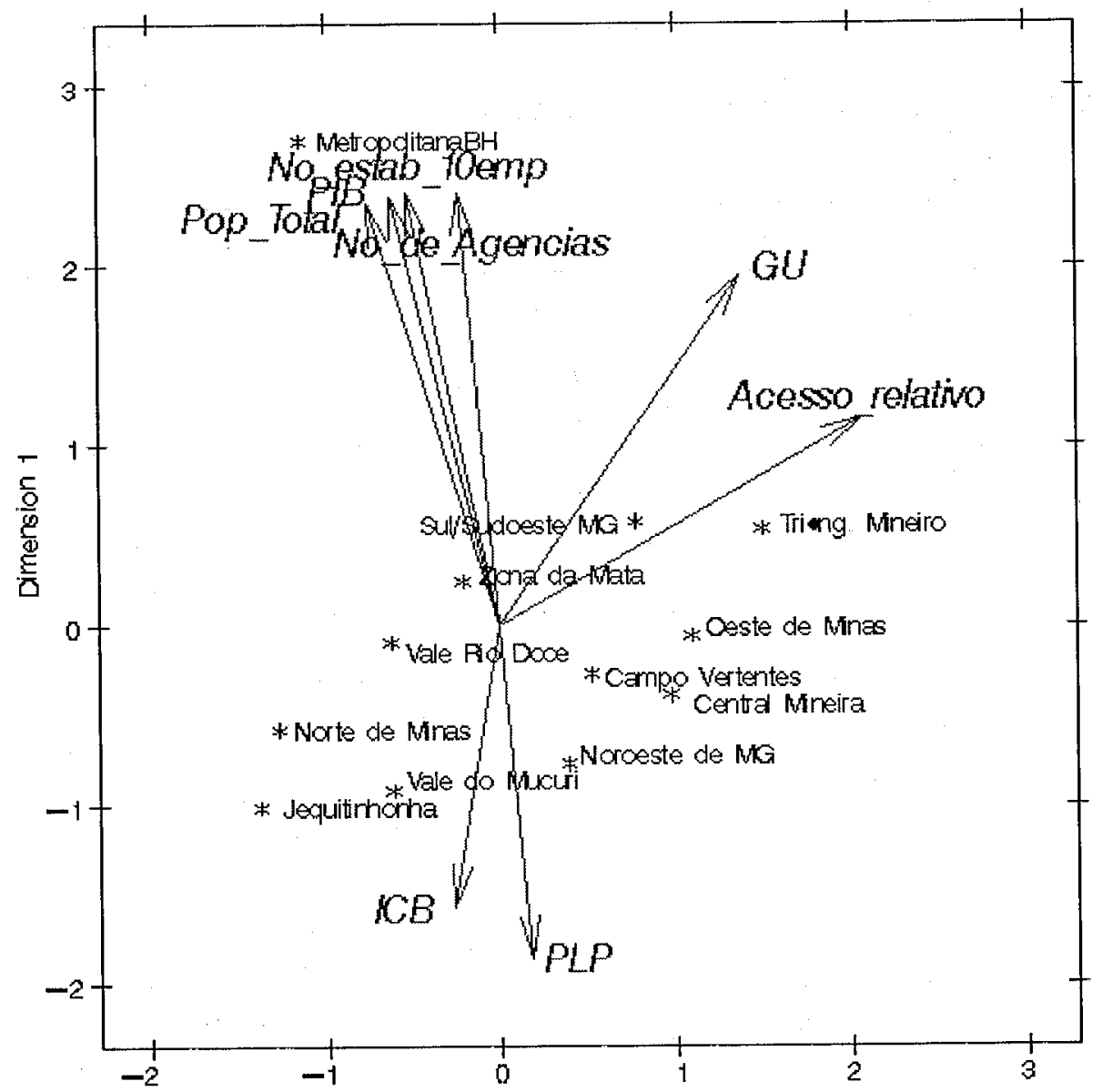

Dimensian 2

Para 1996, como pode ser visto no gráfico 2, as configurações não mudaram significativamente. Apenas a preferência pela liquidez do público diminuiu em termos absolutos em todas as regiōes devido à realocação de portfólio entre depósitos a vista e a prazo pelos 
agentes, ocasionada pelas menores taxas de inflação após o Plano Real. Com esta mudança de valores, a PLP se liga mais ao componente 2. Entretanto, a análise em termos de posicionamento das mesorregiões em função das variáveis em 1996 mantém-se a mesma de 1991.

\section{Gráfico 2: ACP para o ano de 1996}

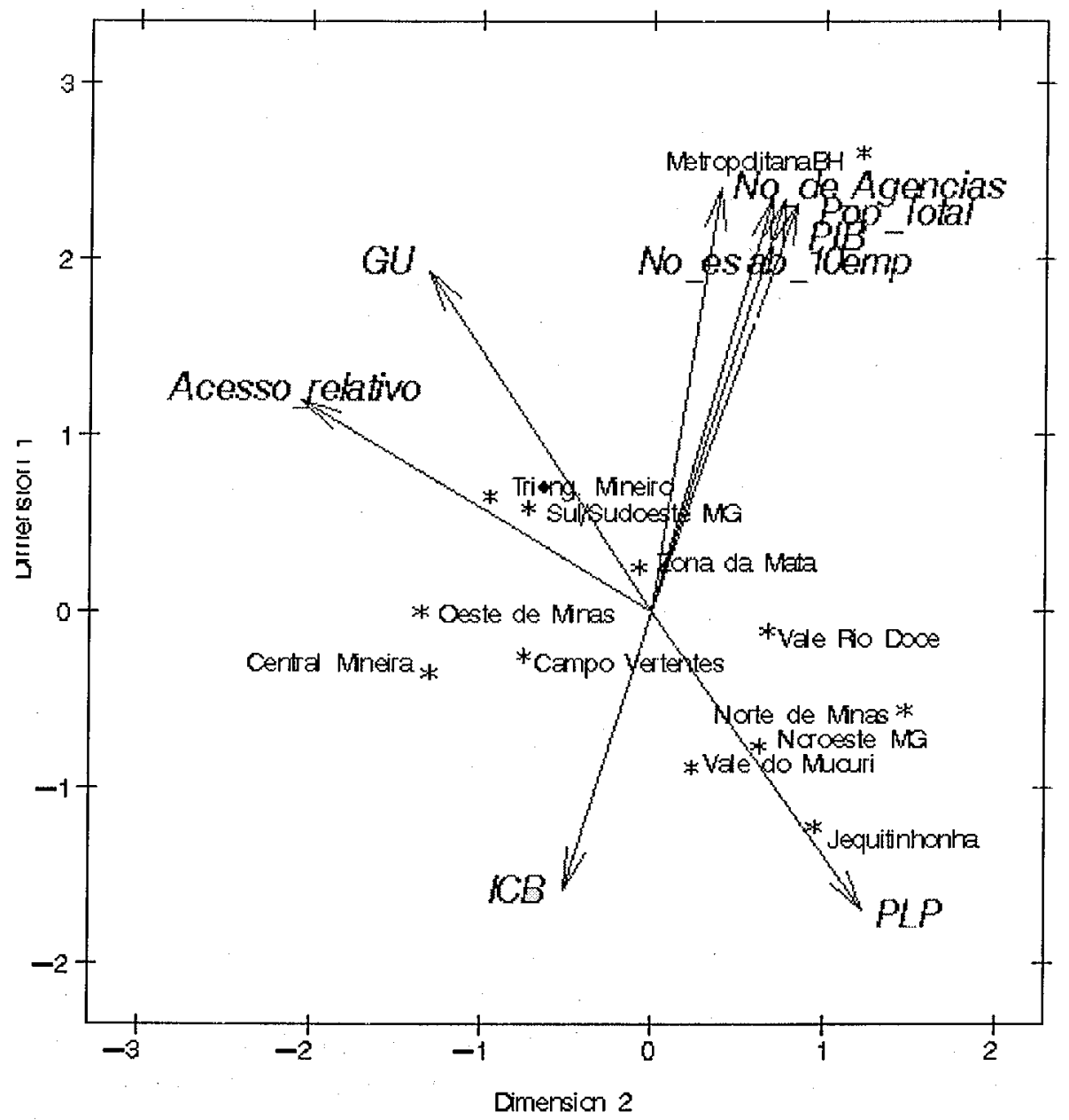

Em 2000, o cenário geral novamente se mantém, com uma distribuição das mesorregiōes bem próximas à de 1991 em termos dos componentes e variáveis. Os resultados podem ser vistos no gráfico 3 a seguir. 
Gráfico 3: ACP para o ano de 2000

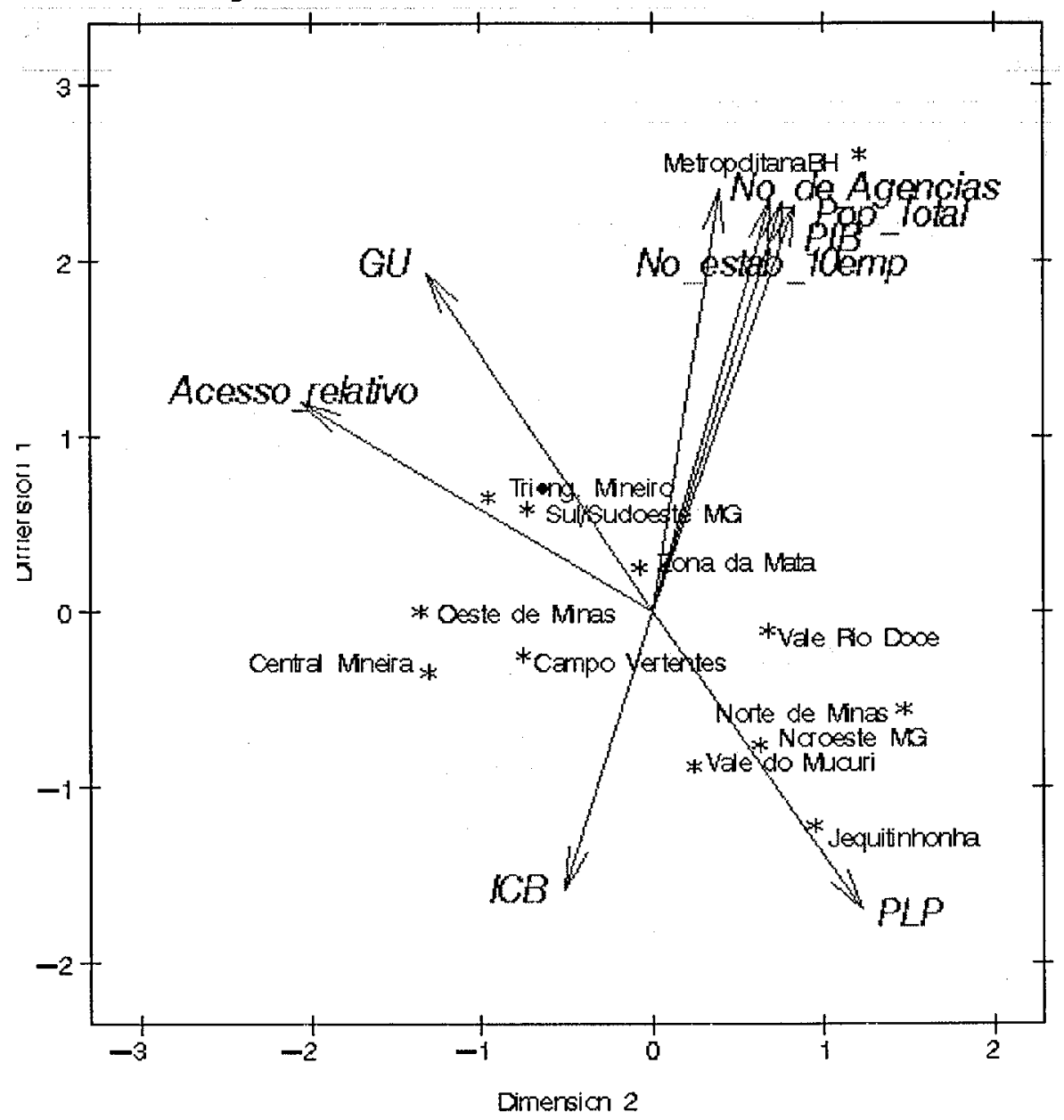

Após esta abordagem inicial sobre os dados tanto financeiros quanto econômicos por meio da ACP, optou-se por realizar-se uma análise de cluster apenas sobre os indicadores financeiros disponíveis: acesso bancário relativo, número de agências e preferência pela liquidez do público. O objetivo é verificar como as mesorregiōes se distribuem em termos de seu comportamento nestas variáveis que indicam acesso bancário e preferência pela liquidez, comportamento este que, como descrito na parte teórica, pode se traduzir em dificuldades na concessão de crédito por parte do sistema bancário. $\mathrm{O}$ artifício de isolar as variáveis financeiras tem o intuito de facilitar à análise estatística e retirar o viés dos resultados, altamente relacio- 
nados ao desempenho econômico. Apesar disso, não se deseja eliminar a relação existente entre a esfera financeira e econômica, simplesmente porque estas estão interligadas por um circuito onde uma depende da outra para existir. O desempenho econômico explica e determina o grau de incerteza das regiões, que, por sua vez, determina o nível de preferência pela liquidez do público, seu acesso a bancos e a atração de agências para a região preestabelecida, o que vai permitir um novo conjunto de alocação dos recursos, via concessão de créditos, e um melhor ou pior desempenho econômico na região. Com isso em mente, verifica-se que a análise de cluster para o ano de 1991 apresentou o dendograma 1.

\section{Dendrograma 1: Análise de cluster usando Average Linkage (Between Groups) para o ano de 1991}

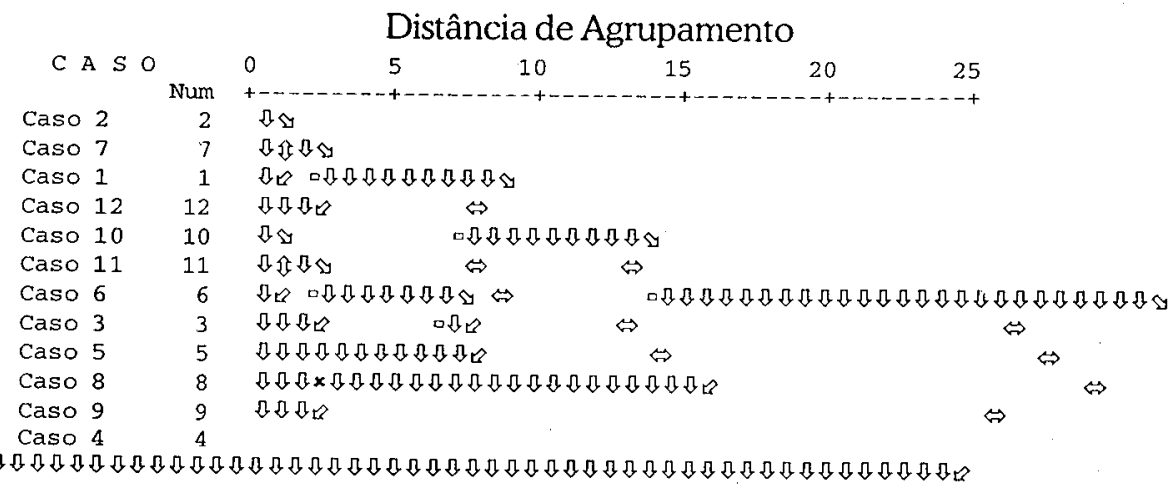

Deste resultado, a divisão ideal mostrou ser a de 5 grupos e a transposição desta divisão bem como sua caracterização a partir dos dados originais é feita no quadro 2 a seguir (cada caso presente no dendograma representa uma mesorregião).

\section{Quadro 2: Agrupamento para o ano de 1991}

\begin{tabular}{|c|c|c|c|c|}
\hline $\begin{array}{c}\text { Grupo } 1 \\
\text { Baixa PLP e } \\
\text { Elevado } \\
\text { número de } \\
\text { Agências } \\
\end{array}$ & $\begin{array}{c}\text { Grupo } 2 \\
\text { Elevado acesso } \\
\text { bancário relativo e } \\
\text { baixa-média PLP }\end{array}$ & $\begin{array}{c}\text { Grupo } 3 \\
\text { Médio acesso } \\
\text { bancário relativo e } \\
\text { baixa-média PLP }\end{array}$ & $\begin{array}{c}\text { Grupo 4B } \\
\text { aixo acesso } \\
\text { bancário } \\
\text { relativo e } \\
\text { média-alta PLP } \\
\end{array}$ & $\begin{array}{l}\text { Grupo } 5 \\
\text { Alta PLP }\end{array}$ \\
\hline \multirow[t]{4}{*}{$\begin{array}{c}\text { 4-Metropolitana } \\
\text { de BH }\end{array}$} & $\begin{array}{c}\text { 9-Triângulo/Alto } \\
\text { Paranaíba }\end{array}$ & 2-Central Mineira & 6-Norte de Minas & $\begin{array}{c}\text { 5-Noroeste } \\
\text { de Minas }\end{array}$ \\
\hline & $\begin{array}{c}\text { 8-Sul/Sudoeste de } \\
\text { Minas }\end{array}$ & 7-Oeste de Minas & 3-Jequitinhonha & \\
\hline & & 1-Campo das Vertentes & 10-Vale do Mucuri & \\
\hline & & 12 - Zona da Mata & $\begin{array}{l}11 \text { - Vale do Rio } \\
\text { Doce }\end{array}$ & \\
\hline
\end{tabular}


O resultado em um cenário espacial é apresentado no mapa 2. As regiōes são apresentadas com um número que indica seu respectivo grupo.

\section{Mapa 2: Agrupamento para 1991}

ESTADO DE MINAS GERAIS MESORREGIÖES GEOGRÁFICAS 1991

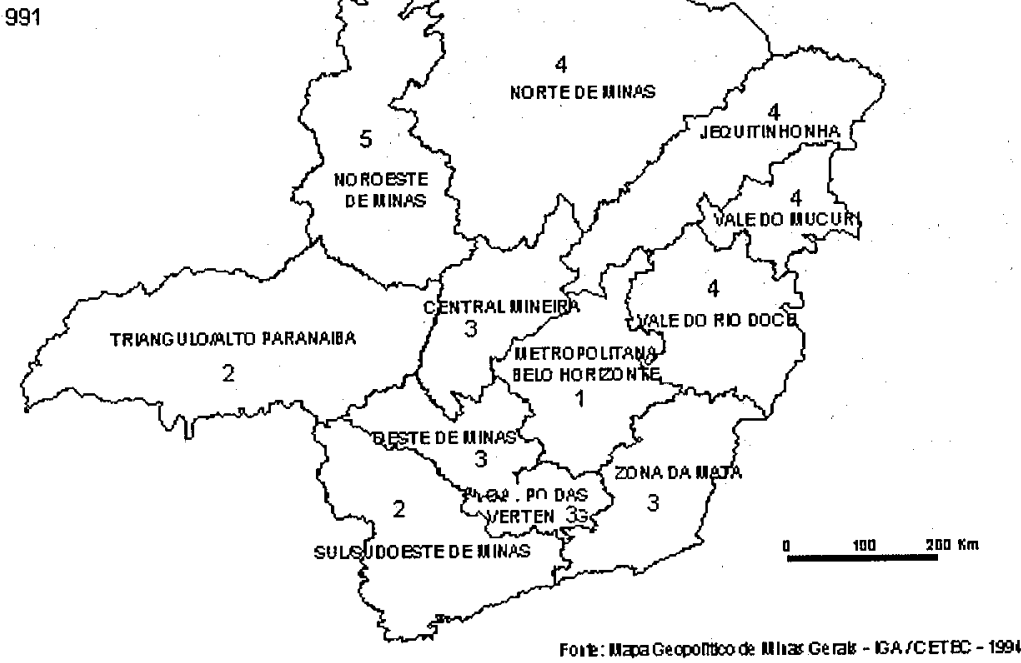

As regiōes do grupo 4, mais ao norte do Estado, apresentam média-alta preferência pela liquidez e baixo acesso bancário. A explicação para este resultado é que são regiōes onde as principais atividades econômicas são agricultura e pecuária e com os menores valores para o PIB per capita do Estado (cerca de $\mathrm{R} \$ 1.500$ ). Apresentam ainda elevado número de analfabetos e população com renda média abaixo de 0,5 salário mínimo. Conforme o estudo de Lemos, M., Guerra, L. e Moro, S. (2000), são regiōes polarizadas por Belo Horizonte na área mais ao sul e pela Bahia na área ao norte. Não apresentam nenhum pólo de crescimento, sendo consideradas regiōes de enclave.

As regiōes do grupo 3 caracterizam-se por posicionamento médio no acesso bancário e baixo-médio na preferência pela liquidez do público. São regiōes com forte presença dos setores da indústria tradicional e com um PIB per capita médio (cerca de $\mathrm{R} \$ 3.000$ ). São regiōes polarizadas por Belo Horizonte e Rio de Janeiro, com destaque para a polarização que esta última área metropolitana exerce sobre a Zona da Mata. 
Nas áreas sul e sudoeste do Estado estão as regiões do grupo 2, de alto acesso bancário relativo e baixa-média preferência pela liquidez. Apresentam elevado PIB e PIB per capita. A região do Triângulo/Alto Paranaíba tem como atividades principais aves, bovinos, café, calçados, cerâmica, laticínios, sucro alcooleiro, cereais, móveis, telecomunicações e turismo. A região Sul/Sudoeste tem como atividades econômicas principais as de laticínio, cerâmica, flores, eletrônico, metal/mecânica e têxtil e vestuário. Como se pode notar, a forte base agrícola comercial da região do Triângulo/Alto Paranaíba explicaria o elevado acesso bancário relativo, pois exige considerável financiamento da produção. Além disto, ambas as regiões acima beneficiaram-se da desconcentração das atividades industriais a partir de São Paulo, o que implicou o transbordamento de atividades modernas para as regiōes, fato que aumentou a demanda por serviços financeiros mais desenvolvidos.

A região metropolitana de Belo Horizonte sozinha compõe o grupo 1 e é caracterizada pelo elevado número de agências bancárias e a baixa preferência pela liquidez, a mais baixa do Estado. É a região com maior PIB e PIB per capita, tendo gerado (45\%) do PIB do Estado em 1991. Apresenta forte peso das indústrias extrativas minerais e das indústrias de transformação. Nesta região está a área circunscrita a Belo Horizonte, um pólo industrial que polariza boa parte do Estado e apresenta elevado grau de terciarização em nível nacional, conforme Lemos, M., Guerra, L. e Moro, S. (2000).

A regiāo Noroeste de Minas compõe o grupo 5. Sua característica mais marcante e que a distingue das demais nas variáveis financeiras é sua elevada preferência pela liquidez, sendo a mais alta do Estado. É uma região com forte atividade econômica no setor de cereais. Apresenta um PIB per capita médio e a mais baixa densidade populacional do Estado. É uma região com fortes ligações econômicas com o Distrito Federal.

Para o ano de 1996, a análise de cluster apresentou os seguintes resultados, vistos no dendograma 2. 
Dendrograma 2: Análise de cluster usando Average Linkage (Between Groups) para o ano de 1996

Distância de Agrupamento

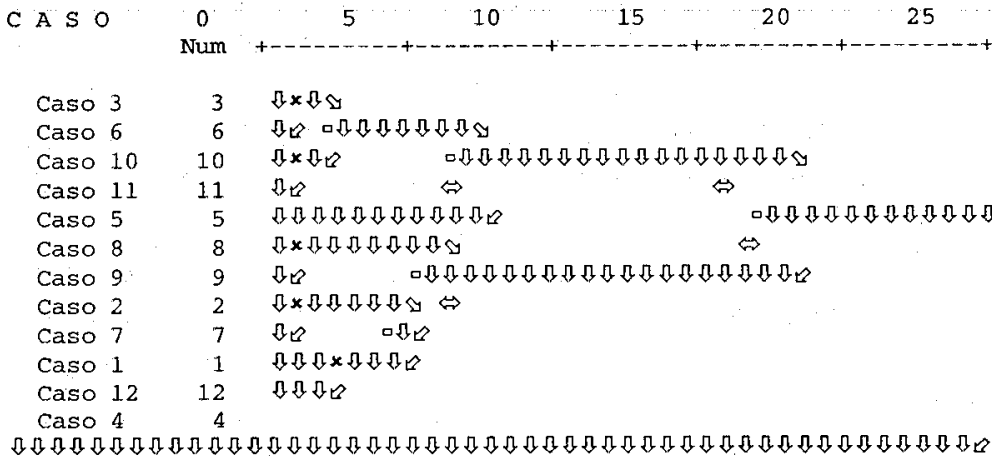

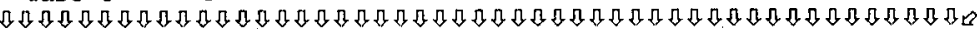

A divisão ideal mostrou ser a de 3 grupos, e a transposição desta divisão bem como sua caracterização a partir dos dados originais é feita no quadro 3 abaixo.

\section{Quadro 3: Agrupamento para o ano de 1996}

\begin{tabular}{|c|c|c|}
\hline $\begin{array}{c}\text { Gaixa PLP e Elevado } \\
\text { número de Agências }\end{array}$ & $\begin{array}{c}\text { Elevado-médio acesso } \\
\text { bancário relativo e } \\
\text { baixa-média PLP }\end{array}$ & $\begin{array}{c}\text { Baixo acesso bancário } \\
\text { relativo e média-alta } \\
\text { PLP }\end{array}$ \\
\hline $\begin{array}{c}\text { 4- Metropolitana de Belo } \\
\text { Horizonte }\end{array}$ & $\begin{array}{c}\text { - Triângulo/Alto } \\
\text { Paranaíba }\end{array}$ & 6- Norte de Minas \\
\hline & 8 -Sul/Sudoeste de Minas & 3 - lequitinhonha \\
\hline & 2 - Central Mineira & 10 -Vale do Mucuri \\
\hline & 7 - Oeste de Minas & \\
\hline & $1-$ Campo das Vertentes & 11 - Vale do Rio Doce \\
\hline & $12-$ Zona da Mata & 5 - Noroeste de Minas \\
\hline
\end{tabular}

O resultado em um cenário espacial é apresentado no mapa 3, novamente com os números nas regiōes representando os grupos a que pertencem. 


\section{Mapa 3: Agrupamento para 1996}

ESTADO DE MINAS GERAIS MESORREGIỐES GEOGRÁFICAS 1996

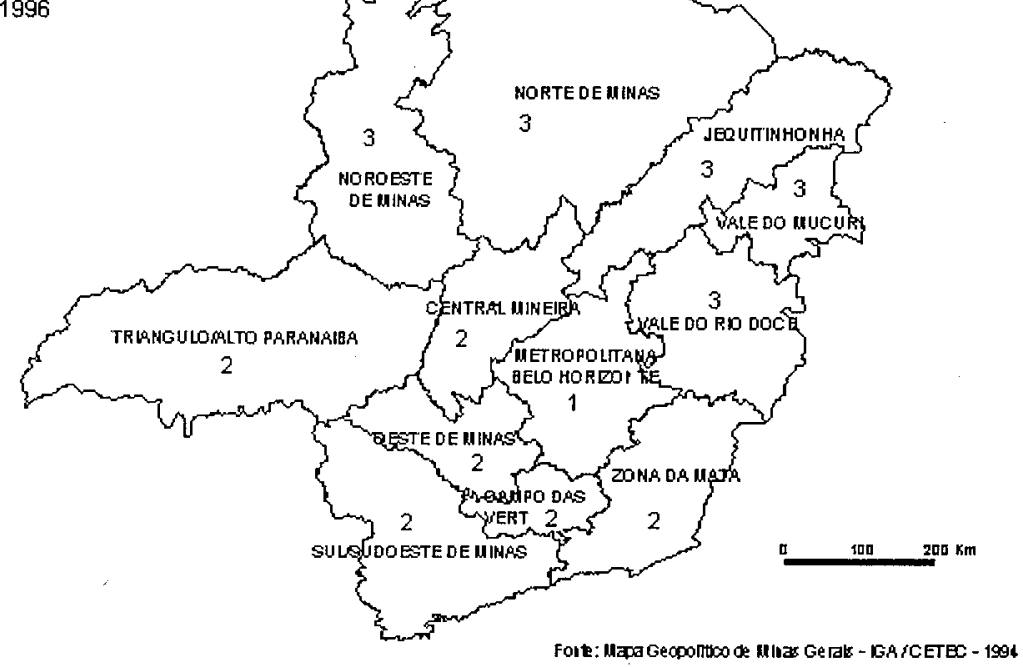

As principais alterações em relação a 1991 foram a inclusão da região Noroeste de Minas no grupo composto pelas mesos do Norte de Minas, Jequitinhonha, Vale do Mucuri, e Vale do Rio Doce e a junçāo dos antigos grupos 2 e 3 em um único grupo. Em relação ao novo agrupamento ao norte do Estado (Noroeste de Minas, Norte de Minas, Jequitinhonha, Vale do Mucuri, e Vale do Rio Doce - regiões com o número 3 no mapa acima), as regiões caracterizam-se pelo baixo acesso bancário e média-alta preferência pela liquidez. Com o fim da inflação, após o Plano Real, ocorreu uma queda na preferência pela liquidez em todas as mesorregiōes do Estado, resultado direto da redução da incerteza derivada do processo inflacionário. A região Noroeste, que era a mais elevada, foi uma das que mais caiu em termos absolutos, de modo que esta região se aproximou das demais do grupo 3, já que o seu elevadíssimo valor da PLP em 1991 era o que a diferenciava das demais de seu atual grupo. A explicação para a forte mudança pode ser o fato de ser esta região a de maior crescimento do PIB no Estado no período.

A junção das regiões que passam a compor o grupo 2, na área centro-sul do Estado, deve-se à aproximação na PLP de ambas. A região metropolitana de Belo Horizonte continua um caso à parte, em função de seu elevado número de agências e a baixa PLP. A análise de cluster para o ano 2000 apresentou o dendograma 3. 


\section{Dendrograma 3: Análise de cluster usando Average Linkage (Between Groups) para 0 ano de 2000}

Distância de Agrupamento

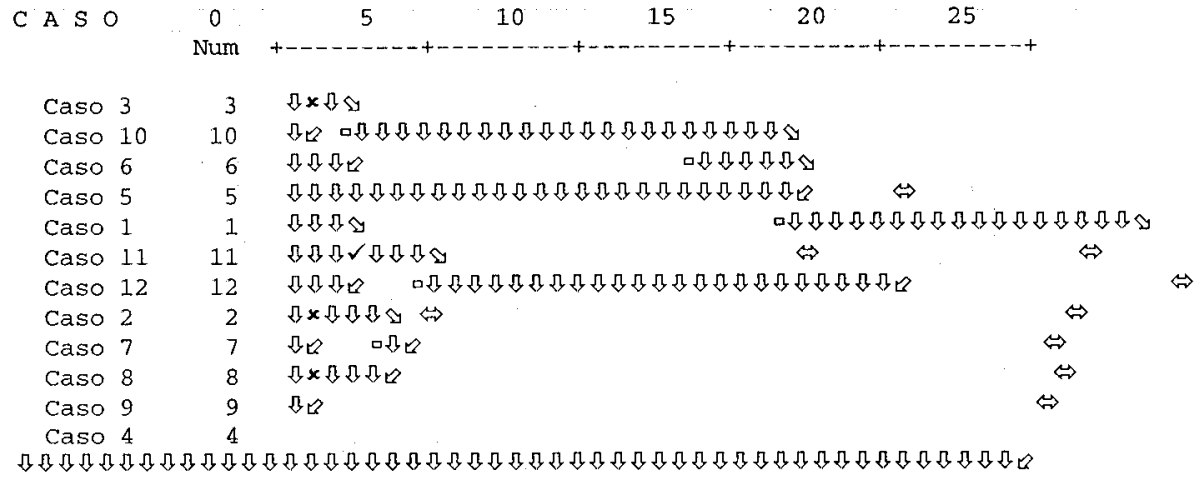

A divisão ideal mostrou ser a de 4 grupos, conforme as caracterizações abaixo. $O$ resultado em um cenário espacial é apresentado no mapa 4.

\section{Quadro 4: Agrupamento para o ano de 2000}

\begin{tabular}{|c|c|c|c|}
\hline $\begin{array}{c}\text { Grupo } 1 \\
\text { Baixa PLP e } \\
\text { elevado número } \\
\text { de Agências } \\
\end{array}$ & $\begin{array}{c}\text { Grupo } 2 \\
\text { Elevado-médio acesso } \\
\text { bancário relativo e } \\
\text { baixa-média PLP }\end{array}$ & $\begin{array}{c}\text { Grupo } 3 \\
\text { Baixo acesso } \\
\text { bancário relativo } \\
\text { e média-alta PLP }\end{array}$ & $\begin{array}{l}\text { Grupo } 4 \\
\text { Alta PLP }\end{array}$ \\
\hline \multirow[t]{7}{*}{$\begin{array}{l}\text { 4. Metropolitana } \\
\text { de Belo Horizonte }\end{array}$} & $\begin{array}{c}9 \text { - Triângulo/Alto } \\
\text { Paranaíba }\end{array}$ & 6- Norte de Minas & $\begin{array}{c}5 \text { - Noroeste } \\
\text { de Minas }\end{array}$ \\
\hline & 8 -Sul/Sudoeste de Minas & 3- Jequitinhonha & \\
\hline & 2 - Central Mineira & 10-Vale do Mucuri & \\
\hline & 7. Oeste de Minas & & \\
\hline & 1 - Campo das Vertentes & & \\
\hline & 12 - Zona da Mata & & \\
\hline & 11 - Vale do Rio Doce & & \\
\hline
\end{tabular}

Fonte: elaboração do autor.

Em 2000, duas alterações ocorrem. Em primeiro lugar, a região Noroeste de Minas separa-se de seu antigo grupo. Isto ocorreu devido a uma elevação de quase $70 \%$ na preferência pela liquidez desta região entre 1996 e 2000, o que a diferenciou acentuadamente em relação às demais regiōes do grupo a que pertencia. A explicação 
para esta alteração na preferência pela liquidez do público na região é uma incógnita, pois o crescimento de seu PIB entre 1996 e 1998 foi um dos mais altos do Estado, cerca de 10\% ao ano. A outra alteração foi a saída da região do Vale do Rio Doce do grupo 3 e sua inclusão no agrupamento representado pelo número 2 no mapa acima. Esta alteração foi devida a uma melhora na preferência pela liquidez de seus agentes, o que a aproxima das demais regiōes do grupo 2 .

As demais configurações continuam como antes, com o grupo 4, mais ao norte, com baixo acesso bancário relativo e média-alta PLP, o grupo 2, na área centro-sul, com elevado-médio acesso bancário relativo e baixa-média PLP e a mesorregiāo Metropolitana de Belo Horizonte como um caso à parte, com baixa PLP e elevado número de agências.

\section{Conclusões}

Minas Gerais tem uma clara separação geográfica entre mesorregiōes em termos de acesso bancário e preferência pela liquidez do público, o que confirma a hipótese da preferência pela liquidez e presença bancária centro-periferia da teoria póskeynesiana. Segundo esta, o comportamento diferenciado da moeda no espaço produziria um círculo vicioso em regiões periféricas. Por serem economicamente atrasadas, essas regiões possuem uma maior incerteza econômica e conseqüentemente uma maior preferência pela liquidez. Este fato dificulta a demanda por investimentos na região, o que, por sua vez, contribui para o atraso da mesma. Assim, o argumento serve para mostrar a necessidade de uma política intervencionista para romper o círculo vicioso. Mais ainda, es. tes resultados corroboram a análise de Crocco, M., Castro, C., Cavalcante, A. (2002) realizada para todo país e permitem verificar que a relação centro-periferia pós-keynesiana que ocorre no espaço econômico nacional se reproduz no espaço econômico regional. As regiões mais ao norte de Minas Gerais (Jequitinhonha, Norte de Minas, Noroeste de Minas, Vale do Mucuri) com fortes ligações com o Distrito Federal e a Bahia apresentam em geral elevadas preferências pela liquidez do público e baixo acesso bancário. Estes fatores podem ser reflexo das características econômicas e sociais destas regiōes, tais como menor integração, baixa produtividade, baixo PIB per capita e população, e podem significar uma menor disponibilidade de crédito para estas regiões por parte do sistema bancário. 
Desta forma, pode-se criar um circulo vicioso nestas regiões onde as características econômicas e sociais induzem a fatores institucionais que dificultam a geração de crédito e isto, por sua vez, dificulta o desenvolvimento econômico, mantendo as características iniciais.

As regiões mais ao centro-sul têm um desempenho econômico melhor, se articulam com economias mais dinâmicas, com Belo Horizonte nas regiões mais centrais, com São Paulo nas regiões mais ao sul e sudoeste e com o Rio de Janeiro, com destaque para a ligação deste centro com a Zona da Mata. Estes fatores induzem a um elevado acesso bancário e baixa preferência pela liquidez do público, de modo que tais regiões apresentam um nível de geração de crédito médio-elevado em comparação com as demais regiōes do Estado, podendo manter um círculo virtuoso na relação entre crédito e désenvolvimento econômico. A regiāo metropolitana de Belo Horizonte é um caso à parte, apresentando elevado número de agências bancárias, cerca de $30 \%$ do número do Estado, e a mais baixa preferência pela liquidez. Esse quadro institucional é reflexo de suas características econômicas, como elevado PIB e PIB per capita, população e grau de urbanização, sendo um centro polarizador tanto no Estado como em nível nacional. É a região onde a geração de crédito teoricamente apresentaria maior facilidade, fator este que a coloca em posição privilegiada no Estado e em condições de manter seus diferenciais nas variáveis econômicas em relação ao resto do Estado.

\section{Referências Bibliográficas}

AMADO, A. Disparate regional development in Brazil. Aldershot: Ashgate, 1997.

ANDRADE, T. A. Métodos estatísticos e econométricos aplicados à análise regional. In: HADDAH, P. (org), Economia regional: teorias e métodos de análise. Fortaleza: BNB, ETENE, 1989.

BARAN, P. A. The political economy of growth. London: John Calder, 1957.

BDMG. Economia mineira - 1989: Diagnóstico e perspectivas. Belo Horizonte: BDMG, 1989.

CARDOSO, F. H. Dependency and development in Latin America. New Left Review, July-August, 1972.

CARDOSO, F. H. Notas sobre o estado dos estudos sobre dependência. Cadernos CEBRAP, n.11, São Paulo, 1973. 
CARDOSO, F. H. Capitalist development and the State: bases and alternatives. Ibero-Americana, v.7, 2, 1978.

CARDOSO, F. H.; FALETTO, E. Dependence and development in Latin America. Berkeley: California Press, 1979.

CARVALHO, F.C. On bank's liquidity preference. In DAVIDSON, P. and J. KREGEL (eds), Full Employment and Price Stability in a Global Economy. Cheltenham: Edward Elgar, 1999.

CROCCO, M., CASTRO, C., CAVALCANTE, A. Polarização Regional, Sistema Financeiro e Preferência pela Liquidez: uma abordagem pós-keynesiana. In: $X X X$ Encontro Nacional de Economia, Nova Friburgo. CD-ROM, 2002.

DAVIDSON, P. Rational expectations: A falacious foundation for studying crucial decision-making processes. Journal of Post Keynesian Economics, New York, v.5, n.2, p. 182-196, dec./jan./feb.1982/83.

DAVIDSON, P. Austrians and post keynesians on economic reality: rejoinder to critics. Critical Review, n. 7, p.423-44, 1993.

DAVIDSON, P. Uncertainty in economics. In: DOW, S.; HILLARD, J (eds.). Keynes, knowledge and uncertainty. Aldershot: Elgar, 1995.

DOW, S. C. The regional composition of the bank multiplier process. Scottish Journal of Political Economy, v.29, 1, p.22-44, 1982.

DOW, S. C. Money and regional development. Studies in Political Economy, v.23, n.2, p. 73-94, 1987.

DOW, S. C. Financial markets and regional economic development: the canadian experience. Aldershot: Averbury, 1990.

DOW, S. C. Money and the economic process. Aldershot: Elgar, 1993.

DOW, S. C. Uncertainty about uncertainty. In DOW, S.C.; HILLARD, J. (eds.). Keynes, Knowledge and Uncertainty. Aldershot: Elgar, 1995.

DOW, S. C. Horizontalism: a critique. Cambridge Journal of Economics, 20, pp. 497$508,1996$.

FAINI, R.; GALLI, G.; GIANINI, C. Finance and development: the case of Southern Italy. In: GIOVANNINI, A. (ed.). Finance and development: issues and experience. Cambridge: University Press, 1993.

FRANK, A. G. Capitalism and underdevelopment in Latin America. New York: Monthly Review Press, 1967.

KALDOR, N. The case for regional policies. Scottish Journal of Political Economy, V.17, 1970.

KNIGH'T, F. H. Risk, uncertainty and profit. New York: Houghton Mifflin, 1991.

LEMOS, M.; GUERRA, L.; MORO, S. A nova configuração regional brasileira: sua geografia econômica e os determinantes locacionais da indústria. In: XXVIII Encontro Nacional de Economia, Campinas. I CD-ROM. 2000. 
MADI, M. A. C.; MELETI, P. M. F. Tendências estruturais dos bancos privados no Brasil: dinâmica da relação entre bancos e empresas não financeiras (1990 1994). Texto para Discussão, n.26, IESP, 1995.

MARDIA, K. V.; KENT, J. T.; BIBBY, J. M. Multivariate analysis. London: Academic Press, 1988.

MYRDAL, G. Economic theory and under-developed regions. London: Gerald Duckworth, 1957.

MOORE, C. L.; HILL, J. M. Interregional arbitrage and the supply of loanable funds. Journal of Regional Science, v. 22, p.499-512, 1982.

PAULA, L.F.R. Dinâmica da firma bancária: uma abordagem não-convencional. Revista Brasileira de Economia, vol. 53, n. 3, pp. 136-142, jul./set., 1999.

PEREIRA, J. C. R. Análise de dados qualitativos. São Paulo: Edusp, 2001.

ROBERTS, R. B.; FISHKIND, H. H. The role of monetary forces in regional economic activity: an econometric simulation analysis. Journal of regional Science, v. 19, p.15-29, 1979.

ROCHA, F. A. S. Evolução da concentração bancária no Brasil (1994-2000), Notas Técnicas do Banco Central do Brasil, n. 11, 2001.

RODRIGUEZ-FUENTES, C. J. Credit availability and regional development. Papers in Regional Science, v. 77, 1, p.63-75, 199.

SAMOLYK, K. A. Banking conditions and regional economic performance. Journal of Monetary Economics, v.34, p.259-278, 1994. 